УДК 81.119

DOI: $10.18384 / 2310-712 X-2015-4-44-50$

\author{
Головнёва Ю.В. \\ Дальневосточный федеральный университет (г. Владивосток)
ИНДИВИДУАЛЬНО-АВТОРСКОЕ ВЫЯВЛЕНИЕ И ЗАМЕЩЕНИЕ (НА ПРИМЕРАХ ИЗ ПРОИЗВЕДЕНИЙ В.В. НАБОКОВА) \\ ЯЗЫКОВЫХ ЛАКУН В СФЕРЕ ВНУТРЕННЕГО МИРА ЧЕЛОВЕКА
}

Аннотация. В статье рассматривается языковое явление, для которого автор вводит рабочее название «индивидуально-авторское выявление и замещение языковых лакун». Анализ индивидуально-авторских концептов сфреры внутреннего мира человека, не имеющих однословного наименования в русском и английском языках, в творчестве В.В. Набокова показывает, что преобладающие средства их наименования писателем - метонимия и типичные словообразовательные модели языка, а метафора играет преимущественно характеризующую эти концепты, не номинативную роль. Сопоставляя данный анализ с анализом описаний одних и тех же чувств в разных языках, выполненным А. Вежбицкой, автор приходит к выводу, что в любых двух разных описаниях некоторого чувства можно вычленить общее ядро и различия - индивидуальные, групповые и национальные.

Ключевые слова: индивидуально ощущаемая языковая лакуна, индивидуально-авторский концепт, внутренний мир человека, метафора.

\title{
Yu. Golovnyova
}

The Far East Federal University, Vladivostok

\section{AN AUTHOR'S INDIVIDUAL IDENTIFICATION AND ELIMINATION OF LANGUAGE LACUNAE IN THE SPHERE OF HUMAN INNER WORLD (BASED ON WORKS BY VLADIMIR NABOKOV)}

Abstract. The subject of the article is a linguistic phenomenon for which the author introduces the term "an author's individual identification and elimination of language lacunae". An analysis of Vladimir Nabokov's individual concepts in the sphere of human inner world that do not have single-word names in the Russian and English languages shows that in Nabokov's texts the prevailing means of their naming are metonymy and typical derivational models; as for metaphor, it contributes mostly to description of these concepts, not to their nomination. Comparing this analysis with Anna Wierzbicka's analysis of descriptions of the same feelings in different languages, the author comes to the conclusion that in any two different descriptions of some feelings you can isolate the common core and differences: individual, group and national ones. Key words: individually felt language lacuna, author's individual concept, human inner world, metaphor.

Феномен лакунизации, или лакунарности, исследуется лингвистами

(с Головнёва Ю.В., 2015. уже несколько десятилетий [20; 21; 13; 17]. При этом под языковой лакуной обычно понимают «отсутствие в од- 
ном из языков, сопоставляемых между собой, наименования того или иного понятия, имеющегося в другом языке» $[19$, с. 71]. В данной статье рассматривается несколько иное языковое явление - языковая лакуна, ощущаемая и заполняемая конкретным автором; рабочим определением языковой лакуны при этом будет просто отсутствие в языке наименования для того или иного понятия (независимо от сопоставления с другим языком).

Индивидуально ощущаемая языковая лакуна отличается от языковой лакуны, выявляемой во время межкультурной коммуникации, тем, что первая распознаётся не в сравнении одного языка с другим, а в сравнении некоторого личного опыта с опытом, закреплённым в лексике языка.

Цель данного исследования - проанализировать характерные примеры языкового явления, которое можно назвать индивидуально-авторским выявлением и замещением лакун в языке (расширив при этом значение термина «языковая лакуна»). Предмет исследования - индивидуальноавторские концепты, относящиеся к семантическому полю внутреннего мира человека. В качестве источников языкового материала были выбраны произведения В.В. Набокова - повесть «Соглядатай» и ряд романов русского и американского периодов. Такой выбор обусловлен тем, что отличительная черта творческой манеры Набокова - его склонность и умение выражать словами то, что до него не было выражено; в его творчестве можно найти немало примеров индивидуального замещения языковых лакун.

Когда речь заходит о сфере внутреннего мира, носителям языка от- носительно часто требуется создание собственных оборотов речи - для выражения личных переживаний. Принято считать, что о многих проявлениях своей внутренней жизни можно говорить лишь метафорами. Поэтому дополнительная задача анализа - выявить функции метафоры в репрезентации индивидуально-авторских концептов данной сферы.

Механизмы создания нового семантического единства из разрозненных прежде смыслов представляют интерес с позиций классической когнитивной лингвистики, а значимость такого концепта в художественном мире автора и в контексте национальной и мировой культуры - с позиций такого направления отечественной когнитивной лингвистики, как лингвоконцептология. Если же речь идёт о концептах чувств, состояний сознания и других проявлений внутреннего мира человека, то познание таких индивидуально-авторских концептов представляет интерес и с позиций психологии - в ней существует метод опосредованного изучения мышления через творения разума и рук человеческих, в том числе через литературу [18, с. 11].

Приведём типичный для произведений Набокова пример индивидуального выявления и заполнения лакуны. Существуют слова "ревность», «зависть», «обида» и даже «мнительность», но нет точного отдельного слова для ощущения, возникшего у персонажа романа «Смотри на арлекинов!» (1974 г.), когда он случайно услышал удачную пародию на себя: "I had the odd sensation of a piece of myself being ripped off and tossed overboard, of my being separated from my own self..." - «Странное я испытывал чувство: как будто от меня 
оторвали кусок и бросили за борт, как будто меня разлучили с моей собственной личностью...» ("Look at the Harlequins!” [7]; перевод Г. Барабтарло [3]). Как видно из перевода, точное слово отсутствует в обоих языках, и, тем не менее, читатель вслед за персонажем явно ощущает здесь лакуну. Отметим этот случай как пример (1); возможно, обозначенное здесь чувство - разновидность мнительности.

Расположим другие обнаруженные нами индивидуально-авторские концепты Набокова в хронологическом порядке издания произведений, в которых они репрезентируются. Некоторые концепты присутствуют в разных произведениях - тогда хронологическому порядку в общем списке будет соответствовать только первое упоминание такого концепта.

Пример (2) - «ищущее, высокое, почти неземное волненье» («Машенька», 1926 г.); ср.: «Очень недолго продолжалось подлинное его увлечение, то состояние его души, при котором Людмила ему представлялась в обольстительном тумане, состояние ищущего, высокого, почти неземного волненья (здесь и далее в изитатах неоднословные номинации индивидуально-авторских кониептов подчёркнуты, а метаборы (в широком смысле, включая сравнения), относящиеся к проявлениям внутреннего мира, выделены полужирным шрибтом. - Ю.Г.), подобное музыке, играющей именно тогда, когда мы делаем что-нибудь совсем обыкновенное - идём от столика к буфету, чтобы расплатиться, - и превращающей это наше простое движенье в какой-то внутренний танец, в значительный и бессмертный жест. Эта музыка смолкла в тот миг, когда ночью, на тряском полу тёмного таксомотора, Людмила ему отдалась, и сразу всё стало очень скучным...» («Машенька» [4]). Судя по другим произведениям Набокова, такое состояние не обязательно вызывается любовным увлечением (достаточно «обыкновенным» действием в художественном мире Набокова) ощущение «высокого волненья» приходит к его героям и на фоне других самых обычных действий.

Пример (3). Сильное сострадание на фоне ощущения предрасположенности окружающего мира к счастью. Ощутимый образ именно этого сильного чувства встречается в художественном мире Набокова как минимум дважды - в романах «Защита Лужина» (1930 г.) и «Пнин» (1957 г.); ср.: «Когда же и в самом деле она встречала обижаемое существо, то было чувство легендарного затмения, когда наступает необъяснимая ночь, и летит пепел, и на стенах выступает кровь, - и казалось, что если сейчас - вот сейчас не помочь, не пресечь чужой муки, объяснить существование которой в таком располагающем к счастью мире нет никакой возможности, сама она задохнётся, умрёт, не выдержит сердце» («Защита Лужина» [2]).

В романе «Пнин» это чувство доведено до степени полной невыносимости; здесь оно не названо отдельным словосочетанием, а передано несколькими предложениями и частями сложных предложений, подчёркнутыми в цитате - такие концепты называют текстовыми: "In order to exist rationally, Pnin had taught himself, during the last ten years, never to remember Mira Belochkin... because, if one were quite sincere with oneself, no conscience, and hence no consciousness, could be expected to 
subsist in a world where such things as Mira's death were possible. $\langle\ldots\rangle$... since the exact form of her death had not been recorded, Mira kept dying a great number of deaths in one's mind... According to the investigator Pnin had happened to talk to in Washington, the only certain thing was that... she was selected to die and was cremated only a few days after her arrival in Buchenwald, in the beautifully wooded Grosser Ettersberg, as the region is resoundingly called. It is an hour's stroll from Weimar, where walked Goethe, Herder, Schiller, Wieland, the inimitable Kotzebue and others. 'Aber warum - but why -' Dr Hagen, the gentlest of souls alive, would wail, 'why had one to put that horrid camp so near!' for indeed, it was near - only five miles from the cultural heart of Germany..." ("Pnin" [8]).

Упоминание красоты, на фоне которой фашисты устроили концлагерь, так действенно именно потому, что совпадает с глубинным строением этого концепта, уже ясным из произведения 1930 г.: та же общая схема - мир, приспособленный для счастья, и невыносимость его уродливых искажений. Сходное переживание (не выраженное словами настолько чётко и ёмко, как в двух названных романах) испытывает также герой романа «Приглашение на казнь» (1938 г.) Цинциннат [5]: он остро ощущает, насколько он «удобно» устроен («моя голова так удобна») и насколько, поэтому, отвратительна насильственная смерть. Если поискать в истории культуры аналог данного концепта, можно вспомнить эпизод из легенды о Гаутаме Будде, перекликающийся с биографией самого Набокова: царевич Гаутама расстаётся с прекрасным миром своей юности и видит за его пределами страдание. Судя по учению Будды о сострадании ко всему живому [16, с. 35], и ему не была чужда способность к описанному Набоковым сильному чувству.

На примере (3) видно, что концепт, не имеющий имени, может представлять собой сложную систему из уже названных в языке концептов, отражать их взаимодействие. В данном случае концепт охватывает взаимосвязь между способностью сострадать и способностью к счастью: чем сильнее ощущаются разнообразные возможности быть счастливым, тем острее ощущение сострадания.

В «Защите Лужина» чувство «легендарного затмения» у невесты главного героя оказывается непонятно - видимо, просто неизвестно - окружающим, и её поведение пытаются объяснить иными причинами: «про неё говорили, что она обожает собак и всегда готова одолжить денег» («Защита Лужина» [2]). Поэтому, «слушая мелкую молву, она чувствовала себя, как в детстве, во время той игры, когда уходишь из комнаты, а другие выдумывают про тебя разнообразные мнения» (там же: [2]); это пример (4) - чувство как во время игры в мнения. Значимость, «неодноразовость» (можно сказать, неокказиональность) данного концепта подтверждает его существенная роль в повести «Соглядатай» (1930 г.) [6].

Пример (5) - «многопланность мышления» - впервые встречается в романе «Дар» (1937-1938 гг. (без 4 главы), первое полное издание 1952 г.). Мышление охватывает «много планов» одновременно - точнее, с точки зрения психологии, в которой описываются подобные феномены, для перехода от восприятия одного плана к восприятию другого требуются на- 
столько ничтожные доли секунды, что эти планы кажутся воспринимаемыми одновременно, - и это доставляет герою изысканное наслаждение. «Вот бы и преподавал то таинственнейшее и изысканнейшее, что он, один из десяти тысяч, ста тысяч, быть может даже миллиона людей, мог преподавать: например - многопланность мышления: смотришь на человека и видишь его так хрустально ясно, словно сам только что выдул его, а вместе с тем нисколько ясности не мешая, замечаешь побочную мелочь - как похожа тень телефонной трубки на огромного, слегка подмятого муравья и (всё это одновременно) загибается третья мысль - воспоминание о каком-нибудь солнечном вечере на русском полустанке, т.е. о чём-то не имеющем никакого разумного отношения к разговору, который ведёшь, обегая снаружи каждое своё слово, а снутри - каждое слово собеседника» («Дар» [1]).

Пример (6) - «чувство звёздного неба» - также впервые встречается в романе «Дар» [1], но разъясняется с помощью метафоры только в романе «Истинная жизнь Севастьяна Найта» (1941 г.) [3]. В каждом из двух романов эточувствоиспытываетглавныйгеройписатель. Фёдор Константинович Годунов-Чердынцев оказывается носителем «очень редкого и мучительного, так называемого чувства звёздного неба, упомянутого, кажется, только в одном научном труде, паркеровском “Путешествии Духа"» («Дар» [1]), - больше в романе об этом чувстве не упоминается. Оно названо по смежности с тем, что его вызывает у персонажа. Характеризуя героя как человека неравнодушного к звёздному небу, такая метонимия всё-таки оставляет его чув- ство за гранью восприятия читателя. За метонимией следует аллюзия. Но читатель, не знакомый с научным трудом Паркера (вполне возможно даже, что здесь мистификация!), едва ли поймёт, о чём речь. Совсем другое дело метафорическая репрезентация этого чувства у Севастьяна Найта: "Years later Sebastian wrote that gazing at the stars gave him a sick and squeamish feeling, as for instance when you look at the bowels of a ripped-up beast" ("The Real Life of Sebastian Knight" [11]). Здесь чувство идентифицируется с помощью метафорического сравнения, благодаря которому читателю нетрудно перенести известное ощущение в новую ситуацию.

Пример (7). Наиболее известный авторский неоднословный концепт Набокова, “cosmic synchronization" (принятый в литературной критике перевод - «космическая синхронизация»), впервые употреблён на английском языке в "Speak, Memory" (1951 г.). В английском варианте автобиографии Набоков пишет об уже упомянутой в примере (6) «многопланности мышления» как о чём-то меньшем, чем «космическая синхронизация»: “That summer I was still far too young to evolve any wealth of "cosmic synchronization"... But I did discover, at least, that a person hoping to become a poet must have the capacity of thinking of several things at a time." Сама же синхронизация разъясняется так: "Vivian Bloodmark, a philosophical friend of mine, in later years, used to say that while the scientist sees everything that happens in one point of space, the poet feels everything that happens in one point of time. Lost in thought, he taps his knee with his wandlike pencil, and at the same instant a car (New York license plate) passes along the 
road, a child bangs the screen door of a neighboring porch, an old man yawns in a misty Turkestan orchard, a granule of cinder-gray sand is rolled by the wind on Venus, a Docteur Jacques Hirsch in Grenoble puts on his reading glasses, and trillions of other such trifles occur-all forming an instantaneous and transparent organism of events, of which the poet (sitting in a lawn chair, at Ithaca, N.Y.) is the nucleus" [9]. В развёрнутую метафору, которой завершается описание концепта, вклинивается название «Итака», содержащее намёк, что Одиссею, способному к космической синхронизации, не обязательно и путешествовать.

Пример (8). "Delicious dissolution" «сладостное саморастворение» (“The Original of Laura”, 2009 г. [10]). Подробнее этот концепт, представляющий собой скрипт - описание необычного умственного действия, состоящего из нескольких этапов, - проанализирован в другой нашей работе [15]. Важный этап этого действия - метафорическое уподобление ментального образа своего тела рисунку на школьной доске, который стирается, а затем восстанавливается.

Во всех перечисленных примерах концепты чувств не получили однословного авторского названия. При их наименовании Набоков использовал метонимию (звёздное небо $\rightarrow$ чувство звёздного неба (=чувство человека при виде неба); фантазия на тему сладостного саморастворения $\rightarrow$ «сладостное саморастворение» как вид умственного действия) или типичные словообразовательные модели языка (мышлением охватывается практически одновременно «много планов» $\rightarrow$ многопланность мышления; ощущаются события, происходящие в Космосе синхронно $\rightarrow$ космическая синхронизачия). Иногда у него при образовании имён встречается метафора: от острого сострадания невозможно жить $\rightarrow$ метафора: «наступает необъяснимая ночь, и летит пепел, и на стенах выступает кровь» $\rightarrow$ «чувство легендарного затмения»; но это скорее окказионализм, не рассчитанный на повторное употребление (по крайней мере, не получивший его в статьях литературных критиков и трудах литературоведов, в отличие от «многопланности мышления» или «космической синхронизации»). В основном метафоры служат для разъяснения индивидуально-авторских концептов писателя - т.е. для характеризации, а не для номинации [12, с. 296].

Подводя итоги, уместно вспомнить, что Анна Вежбицкая, говоря о том, что человеческие чувства часто не могут быть описаны одним словом, ставила вопрос о несовпадении наименований чувств в разных языках. Её семантический анализ разноязычных описаний душевного состояния Христа в Гефсиманском саду показывает, что при переводе названий чувств с языка на язык необходимо учитывать различия между привязанными к словам сходными концептами разных языков [14, с. 548-562]. Если взглянуть на проблему понимания чувств шире, то в любых двух разных описаниях некоторого чувства (как имеющего, так и не имеющего однословное наименование; как на разных языках, так и на одном) можно вычленить общее ядро и различия. Различия могут быть индивидуальными, групповыми (ср. «вдохновение» у поэтов и у бойцов), а также национальными (закреплёнными в разных языках). Для отграничения этих различий, если они существенны, и требуются неоднословные 
наименования и дополнительная характеризация концептов, в том числе метафорическая.

\section{ИСТОЧНИКИ И ЛИТЕРАТУРА:}

\section{Источники:}

1. Набоков В. Дар: Роман. М.: Издания книжной редакции Советско-Британского совместного предприятия СЛОBO, $1990.332 \mathrm{c}$.

2. Набоков В.В. Защита Лужина // Приглашение на казнь: Романы, рассказы, критические эссе, воспоминания. Кишинёв: Лит. артистикэ, 1989. С. 3-148.

3. Набоков В. Истинная жизнь Севастьяна Найта. Пер. Г. Барабтарло. СПб.: Азбука-классика, 2008. 352 с.

4. Набоков В. Машенька: Роман. СПб.: Азбука-классика, 2007. 192 с.

5. Набоков В.В. Приглашение на казнь: Романы, рассказы, критические эссе, воспоминания. Кишинёв: Лит. артистикэ, 1989. $654 \mathrm{c.}$

6. Набоков В.В. Соглядатай // Приглашение на казнь: Романы, рассказы, критические эссе, воспоминания. Кишинёв: Лит. артистикэ, 1989. С. 311-356.

7. Nabokov V. Look at the Harlequins! [Электронный pecypc]. URL: http:// nabokovandko.narod.ru/Texts/Look_at_ the_Harlequins_eng.html (дата обращения: 01.06.2015).

8. Nabokov V. Pnin [Электронный ресурс]. URL: http://nabokovandko.narod.ru/ Texts/Pnin_eng.html (дата обращения: 01.06.2015).

9. Nabokov V. Speak, Memory: An Autobiography Revisited. NY: Vintage Books, 1989. 316 p.

10. Nabokov V. The Original of Laura (Dying Is Fun) // Набоков В.В. Лаура и её оригинал. Фрагменты романа. Пер. с англ. Г. Барабтарло. СПб.: Азбука-классика, 2010. P. 105-384.
11. Nabokov V. The Real Life of Sebastian Knight. New York, 1992. 203 p.

\section{Литература:}

12. Арутюнова Н.Д. Метафора // Лингвистический энциклопедический словарь / Гл. ред. В.Н. Ярцева. М.: Советская энциклопедия, 1990. С. 296-297.

13. Быкова Г.В. Лакунарность как категория лексической системологии: дис. ... докт. филол. наук: 10.02.19. Воронеж, 1999. 368 c.

14. Вежбицкая А. Семантические универсалии и базисные концепты. М.: Языки славянских культур, 2011. 568 с.

15. Головнёва Ю.В. Концепт "delicious dissolution" в незавершённом романе Набокова "The Original of Laura"// Вестник ТГПУ. Томск, 2014. №7. С. 197-203.

16. Леонтьева Е. Путеводитель по буддизму. Иллюстрированная энциклопедия. М.: Эксмо, 2012. 253 с.

17. Макаров Д.М. Эмотивная лакунарность и способы ее элиминирования в художественном переводе: на материале романа М.А. Шолохова "Тихий Дон» и его перевода на английский язык: дис. ... канд. филол. наук: 10.02.20. Пятигорск, 2010. 195 с.

18. Панкратова С.А. Когнитивно-семантические механизмы метафорического выбора: монография. СПб.: Изд-во РГПУ им. А.И. Герцена, 2009. 102 с.

19. Попова З.Д., Стернин И.А. Лексическая система языка: учеб. пособие. Воронеж: Изд-во Воронежского государственного ун-та, 1984. 149 с.

20. Сорокин Ю.А. Роль этнопсихологических факторов в процессе перевода // Национально-культурная специфика речевого поведения. М.: Наука, 1977. 175 с.

21. Сорокин Ю.А., Марковина И.Ю. Опыт систематизации лексических и культурологических лакун // Лексические единицы и организация структуры литературного текста. Калинин, 1983. С. 58-73. 